\title{
N92-14359
}

\section{SUPPRESSION OF SUBSYNCHRONOUS VIBRATION IN THE SSME HPFTP}

\author{
David G. Becht, Larry A. Hawkins, Joseph K. Scharrer, \\ and Brian T. Murphy \\ Rockwell International \\ Canoga Park, Cali fornia 91304, U.S.A.
}

\begin{abstract}
SSME HPFTP hot-fire dynamic data evaluation and rotordynamic analysis both confirm that two of the most significant turbopump attributes in determining susceptibility to subsynchronous vibration are impeller interstage seal configuration and rotor sideload resulting from turbine turnaround duct configuration and hot gas manifold. Recent hot-fire testing has provided promising indications that the incorporation of roughened "damping" seals at the impeller interstages may further increase the stability margin of this machine. A summary of the analysis which led to the conclusion that roughened seals would enhance the stability margin is presented herein, along with a correlation of the analysis with recent test data.
\end{abstract}

\section{NOMENCLATURE}

DN Bearing Bore Diameter ( $\mathrm{mm}$ ) times shaft speed ( $\mathrm{rpm}$ )

FMOF First Manned Orbital Flight

FPL Full Power Level

FWR Forward Wear Ring

Grms Accelerations ( $G^{\prime} s$ ) root mean square

HPFTP High Pressure Fuel Turbopump

HGM Hot Gas Manifold

LOSI Linear Onset Speed of Instability

RWR Rear Wear Ring

SSME Space Shuttle Main Engine

TAD Turnaround Duct

INTRODUCTION

Since SSME testing began in mid-1975, it became apparent that two of the key design features which determined the high pressure fuel turbopump's susceptibility to subsynchronous vibration were the interstage seal configuration and the turbine turnaround duct configuration (affecting aerodynamic sideload). The purpose of this paper is to present the evolution of the design and supporting rotordynamic analyses of the turbopump, which ultimately led to increased stability margin and the elimination of subsynchronous vibration from the SSME HPFTP.

\section{TURBOPUMP DESCRIPTION}

A cross section of the SSME HPFTP rotor is shown in figure 1. Its rotating assembly weight of only $578 \mathrm{~N}$ (130 lbs), combined with a maximum rating of $57.4 \mathrm{MW}$ (77,000 $\mathrm{hp}$ ), makes it one of the highest power-to-weight ratio machines ever built. Table 1 
shows some of the more significant operating parameters associated with the Full Power Level (FPL) rating.

The turbopump consists of three identical pump stages driven on a common built-up shaft by a two stage turbine. The shaft is supported radially by two pairs of preloaded duplex bearings. All four bearings have $45 \mathrm{~mm}$ bores, and operate at a DN in excess of 1.6 million. The outer race of each bearing can slide axially in its housing to accommodate shaft growth/contraction and small amounts of axial travel brought on by changes in thrust balance. Transient thrust imbalances experienced during start-up and shut-down are reacted by an additional mechanical bearing at the pump end of the shaft. During mainstage operation $(>12,000 \mathrm{cpm})$, the shaft ifts off this bearing as a balance piston, integral with the third stage pump impeller, becomes active.

The turbopump has a pair of high-pressure interstage seals located between the lst and 2 nd stage pump impellers and the 2 nd and 3 rd stage pump impellers. The influence of these interstage seals, along with the aerodynamic sideload generated by the turbine discharge gases flowing through the turnaround duct and hot gas manifold, on the rotordynamics of the turbopump is appreciable, as will be developed later.

\section{DISCUSSION OF SUBSYNCHRONOUS VIBRATION}

Two primary mechanisms are postulated as potential causes of turbopump subsynchronous vibration of the type experienced on this machine: 1) forced vibration response due to interaction of the rotor with a support nonlinearity such as bearing deadband, and 2) self-excited rotor whirl at the first rotor mode frequency.

The first mechanism, called deadband interaction, refers to the behavior of a rotor passing through the bearing deadband clearance of at least one of its bearings. If a rotor's orbit passes through the bearing deadband, it will experience reduced effective stiffness compared to an orbit which does not pass through the deadband. This reduced stiffness may potentially lower the rotor vibration mode frequencies. If the rotor is operated at a speed that is just less than twice the natural frequency of a rotor mode, deadband interaction can lower the frequency of that mode to one half of the operating speed. The synchronous forcing function (unbalance) may then excite the second harmonic of this mode, causing all harmonics and the fundamental to respond. The result is a forced vibration response of the rotor mode at $50 \%$ of the synchronous frequency. This phenomenon is well documented in papers by Ehrich, Bently, and Childs (references 1-3). In the SSME HPFTP operating at FPL, the synchronous speed is 1.8 to 1.9 times the predicted first rotor mode frequency. Thus, subsynchronous vibration at $50 \%$ of the synchronous frequency can result if conditions are correct for deadband interaction.

The second mechanism, referred to as limit cycle whirl, can occur with any machine that possesses whirl drivers capable of causing one of the rotor modes to become unstable. If a rotor mode becomes linearly unstable, its orbit will grow until some nonlinearity in the system limits further growth. Such nonlinearities may be 1) the nonlinear load-deflection characteristic of ball bearings or other rotor support elements, and 2) light rubbing at various seal locations.

The potential whirl drivers in the HPFTP include cross-coupled stiffness of the pump impellers or impeller interstage seals, turbine aerodynamic forces, and internal rotor friction. Current estimates for the interstage seal coefficients, bearing stiffnesses, and other rotor support parameters result in a rotor that has a 1 inear 
stability threshold speed greater than 50,000 cpm. However the nonlinear stability threshold could be less than the linear value due to interaction of the rotor with system nonlinearities such as bearing deadband. Since the linear first mode is nominally $52 \%$ to $55 \%$ of synchronous, limit cycle whirling of the first mode could produce $47 \%$ to $52 \%$ subsynchronous vibration response.

\section{ROTORDYNAMIC ANALYSIS AND TEST RESULTS}

Rotordynamic Model The linear elastic model of the rotating assembly (shown in figure 2) is comprised of cylindrical and tapered finite element beam elements. Complete descriptions of the model and the solution technique are presented by Murphy et al. (ref. 4).

All of the key elements in the model are defined throughout the turbopump operating speed range using appropriate computer codes. Ball bearing load-deflection curves are obtained using an industry standard quasi-static rolling element bearing program by Jones (ref. 5). The bearing stiffness is then combined in series with a bearing support stiffness before input to the rotordynamic model. The relatively small rotordynamic coefficients for the impeller wear ring seals were estimated using results from the short seal analysis of Childs (ref. 6), since no theory currently exists to adequately predict rotordynamic coefficients for incompressible flow labyrinth seals. The turbine interstage seal coefficients were calculated using the analysis by Scharrer (ref. 7). Both turbine stages are unshrouded, and the load split between them is $50 / 50$, so experience dictates that the aerodynamic crosscoupling be based on an efficiency factor of $B=1.5$ (ref. 8): Interstage seal coefficients for the roughened seal configuration are calculated with a bulk flow model for arbitrary clearance functions (ref. 9). Table 2 lists all these coefficients for the FPL rating.

Nonlinear Analysis As outlined previously, the proposed scenarios by which subsynchronous vibration is generated in the HPFTP all involve interaction of the rotor with nonlinearities in its support elements. Therefore meaningful predictions of subsynchronous response can only be performed using a nonlinear rotordynamic model, specifically performing a transient simulation. In this nonlinear simulation model, the equations of motion are integrated numerically with time to yield steady state responses. Due to the on/off nature of some of the nonlinearities, all results reported herein employed first order integration schemes with a time step of about 12 microseconds.

In the so called deadband interaction scenario, where subsynchronous vibration would nominally be at $50 \%$ of pump speed, the nonlinear model can easily be made to exhibit this phenomenon by adjusting the eccentricities, bearing deadband, and unbalance distribution (a11 wel1 within expected tolerance bands). For cases where the vibration is at other than $50 \%$, it has been hypothesized that it is a 7 imit cycle whirl of the first rotor mode. This type of motion has also been simulated with the nonlinear rotordynamic model. To achieve this, however, it was found necessary to lower the logarithmic decrement of the first mode by altering the bearing and interstage seal coefficients. Changes to the coefficients on the order of $5 \%$ to $10 \%$, in addition to reducing the static sideloads by $25 \%$, were necessary to bring on the limit cycle whirl. These changes reduced the log dec by about half, while still maintaining a linear onset speed of instability (LOSI) greater than 50,000 cpm.

Numerous studies of HPFTP subsynchronous vibration behavior have been conducted employing both the deadband interaction and the limit cycle whirl models. The 
standard approach is to adjust mass and seal eccentricities to match measured synchronous and subsynchronous housing acceleration levels for a given test of a particular unit. This model is then used as a basis for investigating the sensitivity of the HPFTP to various parameter changes. One of the more comprehensive studies was done by matching the model to a particular Phase II unit which displayed 4.0 Grms of synchronous vibration and 1.5 Grms of $50 \%$ subsynchronous vibration at 109\% power level. Figure 3 shows typical results employing the deadband interaction mechanism to induce the subsynchronous vibration, and in this case shows how variations in turbine sideload affects the amplitude of the synchronous and subsynchronous vibration components.

Influence of Interstage Seal Design For the original three stepped 1abyrinth seal design incorporated prior to the whirl problem, the LOSI was predicted to be about $20,000 \mathrm{cpm}$ (ref. 10). With the incorporation of the stepped smooth seals, the predicted LOSI was increased to about $40,000 \mathrm{cpm}$. Additional stiffness in the ball bearing support structures was also an important contributor to this increase. Subsequent engine testing confirmed these predictions, as it was possible to operate up to full power level. However, the HPFTP henceforth experienced moderate levels of subsynchronous vibration, and an increase in stability margin was considered desirable. An example of housing accelerometer data typical of this configuration turbopump is shown in figure 4 . In this particular test, the subsynchronous vibration frequency was at approximately $53 \%$ of synchronous, and comparable to synchronous in amplitude during certain portions of the test. Several tests with this configuration turbopump al so showed subsynchronous vibration amplitudes greater than synchronous.

Rotordynamic analyses performed subsequent to the 1976 whirl investigation indicated that the stability margin of the pump could be further enhanced by changing the configuration of the impeller interstage seals from the 3 -stepped smooth to a straight smooth design. This would effectively increase the stiffness and damping coefficients generated by the seals, and the LOSI was predicted to be greater than $50,000 \mathrm{cpm}$. Many model parameters are not valid beyond 50,000 cpm, so the actual value is not relevanc. Engine test results, given in table 3 , confirmed that the amplitude of subsynchronous vibration decreased significantly with the incorporation of the straight smooth interstage seal configuration. The percentage of turbopumps which displayed detectable levels was also somewhat lower, as indicated in table 3.

The goal of eliminating subsynchronous vibration completely led to consideration of other interstage seal configurations, specifically the straight rough design. Rotordynamic analyses performed as early as 1983 predicted that the stability margin of the HPFTP could be further enhanced by changing the impeller interstage seal configuration from the straight smooth to a straight rough design, which was predicted to provide increased damping by the seals for just a slight decrease in stiffness.

Since LOSI could not be used as an indicator of relative stability, a logarithmic decrement criteria was established at this point. A comparison of first mode log $\mathrm{dec}^{\prime} \mathrm{s}$ at FPL shows the straight smooth configuration at 0.14 , while the straight rough configuration has a $\log \mathrm{dec}$ of 0.22 . Therefore enhanced stability margin would be expected for turbopumps incorporating the roughened interstage seal design.

Influence of Turn Around Duct Design At approximately the same time as the change from a 3-stepped to a straight smooth seal, a change was proposed for the turbine turnaround duct design which was intended to improve turbine efficiency and reduce the turbine temperatures. This new design came to be known as the FPL turnaround 
duct configuration, and was incorporated into the development configuration of the HPFTP in 1981, soon after the straight smooth interstage seals. A block change was subsequently made to the pump design, incorporating these and other rotordynamically less significant modifications, the resulting configuration henceforth referred to as Phase I.

It was eventually determined that the analytical tools available at that time did not adequately predict the turbine aerodynamic effects, and the FPL turnaround duct actually had higher resistance and greater transverse pressure differential across the turbine than the FMOF configuration. This had the effect of increasing the aerodynamic sideload acting on the rotor to about 1.33 times that of the FMOF duct. As illustrated in figure 3 , this increase in sideload was predicted to suppress subsynchronous vibrations. This prediction was verified by test, with almost no occurrences of subsynchronous vibration ever experienced on the Phase I HPFTP.

After considerable ground testing and flights with the Phase I HPFTP, it became apparent that the reduced turbine efficiency and higher tempuratures generated by the FPL turnaround duct were detrimental to the 1 ife of the turbine blades, and the turnaround duct configuration had to be returned to the FMOF design, except with thicker sheet metal walls (called FMOF II). Again, this modification along with several other rotordynamically less significant changes were instituted in a block - change in 1985, with the resulting configuration referred to as Phase II.

Influence of Hot Gas Manifold Design Since modifications to the turbine turnaround duct had failed to be effective in reducing the resistance to turbine hot gas flow, a different approach was subsequently adopted. With the advent of improved aerodynamic analysis techniques, such as CFD analysis, it was determined that one significant contributor to turbine flow resistance was the relatively inefficient 3 -duct hot gas manifold used to channel the turbine discharge flow from the turbopump to the main injector. A design alternative was proposed, which predicted that two recontoured ducts could transfer the hot gas more efficiently than the current 3 -duct

arrangement, thus reducing turbine back pressure and turbulence in the hot gas flow. A further consequence of this modification was predicted to be lower transverse pressure across the turbine and correspondingly lower rotor aerodynamic sideload. As predicted in figure 3 , the reduced sideload (about $0.56 \times$ FMOF sideload) would be expected to increase the amplitude and frequency of occurrence of subsynchronous vibration in a Phase II HPFTP used in conjunction with a 2-duct hot gas manifold.

Coincidently, the first 2-duct hot gas manifold powerhead and the first HPFTP to incorporate straight rough interstage seals were completed and ready for development testing at approximately the same time, May 1989. To minimize the risk of testing a new powerhead design with an unproven HPFTP design, the 2-duct hot gas manifold engine was first tested with a Phase II pump that had significant test time on other engines and had not experienced subsynchronous vibration. However, with its first test on the 2-duct HGM engine, it exhibited subsynchronous vibration at rated power level, as illustrated in figure 5, which Phase II pumps rarely ever did. Based on other performance data, it was verified that the turbine had achieved the predicted reduction in turbulence and transverse pressure differential. Consequently, the appearance of subsynchronous vibration in this Phase II pump confirmed the predicted reduction in stability margin resulting from the lower rotor sideload.

The next test on the 2-duct HGM engine was conducted with the first roughened interstage seal turbopump, and it did not experience subsynchronous vibration at any power level, as shown in figure 6 . Since that time, the straight rough interstage seals have been tested in 3 different turbopumps, a total of 23 tests and over 12,000 
seconds on several different engines, including both the 2-duct and 3-duct HGM, and encompassing all power levels up to and including FPL. None of the tests to date have shown any indication of subsynchronous vibration on this configuration HPFTP. Turbopumps which incorporate this change are currently being prepared for certification as part of the sustained flight configuration.

\section{CONCLUSION}

In general, the stability trends observed throughout the HPFTP test history have been simulated quite accurately by the current rotordynamic model. Two points continue to be reinforced through all the numerous parametric studies performed with this model. First, the stability ratio of the interstage seal configuration, evolving from stepped labyrinth to stepped smooth to straight smooth and eventually to straight rough, always had a significant influence on the machine's susceptibility to subsynchronous vibration and its associated amplitude. Second, the same conclusion can be made regarding the influences of aerodynamic sideload, as its contributing components evolved from FMOF I TAD to FPL TAD to FMOF II TAD to 2-duct HGM. Finally, it appears that a long standing goal of increasing the stability margin sufficiently to totally suppress subsynchronous vibration in this machine may be realized through the incorporation of straight rough impeller interstage seals.

\section{REFERENCES}

1. Ehrich, F. F., "Subharmonic Vibrations of Rotors in Bearing Clearance", ASME Paper 66-MD-1, Design Engineering Conference and Show, Chicago, I11., May 1966.

2. Bent7y, D., "Forced Subrotative Speed Dynamic Action of Rotating Machinery", ASME Paper 74-PET-16, Petroleum Mechanical Engineering Conference, Dallas, Texas, Sept 1979.

3. Childs, D. W., "Fractional-Frequency Rotor Motion Due to Nonsymmetric Clearance Effects", ASME Paper 81-GT-145, International Gas Turbine Conference and Products Show, Houston, Texas, March 1981.

4. Murphy, B.T., Scharrer, J.K., and Hawkins, L.A., "The SSME HPFTP Wavy Interstage Seal: Part II-Rotordynamic Analysis", ASME Publication DE-Vol. 18-2, Machinery Dynamics - Applications and Vibration Control Problems, 1989, pp. 95-100.

5. Jones, A. B., "A General Theory for Elasically Constrained Ball and Radial Roller Bearings Under Arbitrary Load and Speed Conditions", ASME Journal of Basic Engineering, Vol. 82, 1960, p. 309.

6. Childs, D. W., "Dynamic Analys is of Turbulent Annular Seals Based on Hir's Lubrication Equation", ASME Journal of Lubrication Technology, Vol. 105, No. 3, 1983, pp. 437-445.

7. Scharrer, J.K., "Theory Versus Experiment for the Rotordynamic Coefficients of Labyrinth Gas Seals: Part I-A Two Control Volume Model, "ASME Transactions Journal of Vibrations, Acoustics, Stress, and Reliability in Design, Vol. 110, No. 3, July 1988, pp. 270-280.

8. Alford, J.S., "Protecting Turbomachinery From Self-Excited Rotor Whirl", ASME Journal of Engineering for Power, 1965, pp. 333-344. 
9. Scharrer, J.K. and Nunez, D.J., "The SSME HPFTP Wavy Interstage Seal: Part I-Seal Analysis", Publication DE-Vol. 18-2, Machinery Dynamics - Applications and Vibration Control Problems, 1989, pp. 101-108.

10. Childs, D. W., "The Space Shuttle Main Engine High Pressure Fuel Turbopump Rotordynamic Instability Problem", ASME Journal of Engineering for Power, Vol. 100, 1978, pp. 48-57.

Table 1. FPL Operating Parameters for SSME HPFTP

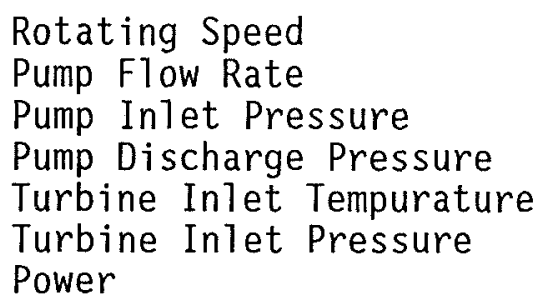

Rotating Speed

Pump Flow Rate

Pump Discharge Pressure

Turbine Inlet Tempurature

Power

Table 2. Rotordynamic Coefficients for Rotor Support Elements

\begin{tabular}{lrrc} 
& $\begin{array}{c}\text { Kxx } \\
(1 b s / i n)\end{array}$ & $\begin{array}{c}\text { Kxy } \\
(1 b s / i n)\end{array}$ & $\begin{array}{c}\text { Cxx } \\
(1 b-s e c / i n)\end{array}$ \\
\cline { 2 - 4 } & & & \\
Ba11 Bearing (W/ Support) & 370,000 & & \\
1st Stage Imp FWR+RWR & 45,000 & 5,000 & 2.7 \\
2nd Stage Imp FWR+RWR & 29,000 & 4,600 & 2.5 \\
3rd Stage Imp FWR & 7,700 & 1,500 & 0.0 \\
Turbine Interstage Sea1 & 3,300 & 2,800 & 1.5 \\
Alford's (each turb stage) & & 18,700 & 106 \\
l-2 Pump Interstage Seal & 460,000 & 253,000 & 106 \\
2-3 Pump Interstage Seal & 460,000 & 253,000 & 106
\end{tabular}

Table 3. Occurrence of Subsynchronous Vibration with the Three Stepped and Straight Smooth Seals

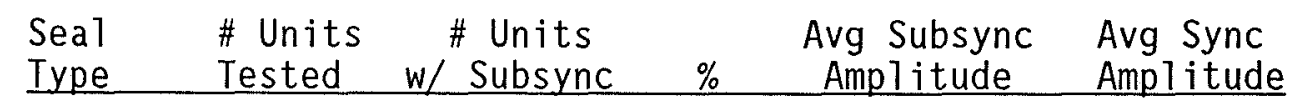

$\begin{array}{llllll}\text { Three Step } & 63 & 13 & 21 \% & 5.1 \mathrm{Grms} & 5.9 \mathrm{Grms} \\ \text { Str Smooth } & 70 & 12 & 17 \% & 1.2 \mathrm{Grms} & 4.9 \mathrm{Grms}\end{array}$




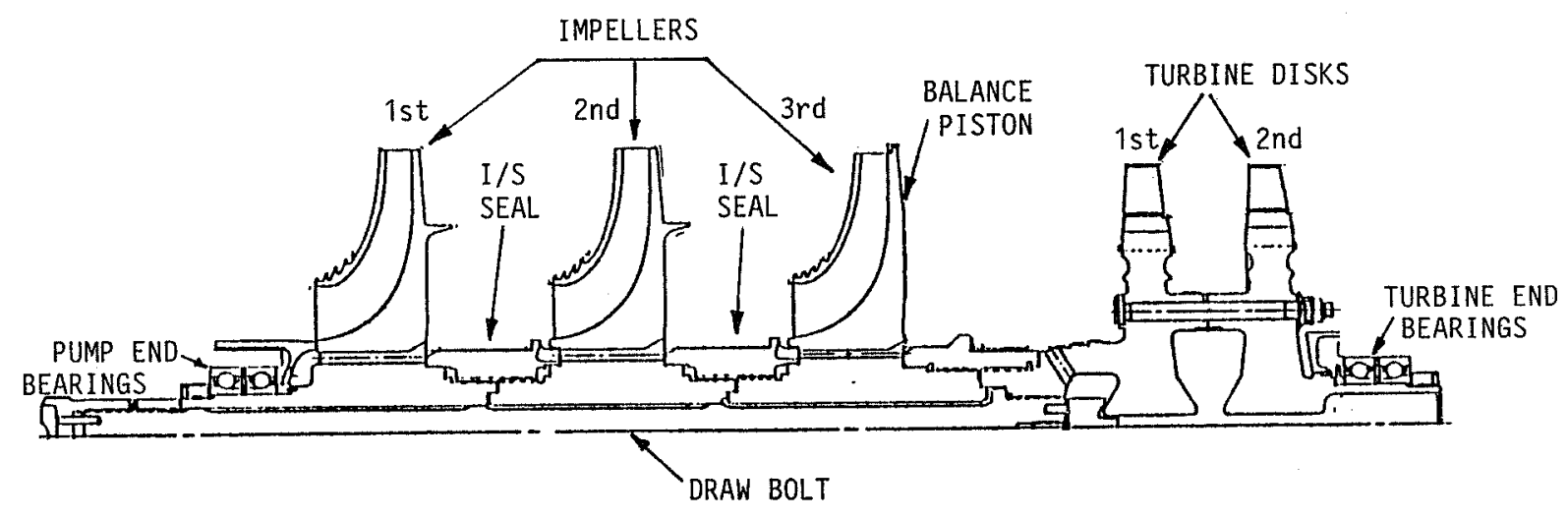

FIGURE 1. HALF CROSS SECTION OF HIGH-PRESSURE FUEL TURBOPUMP

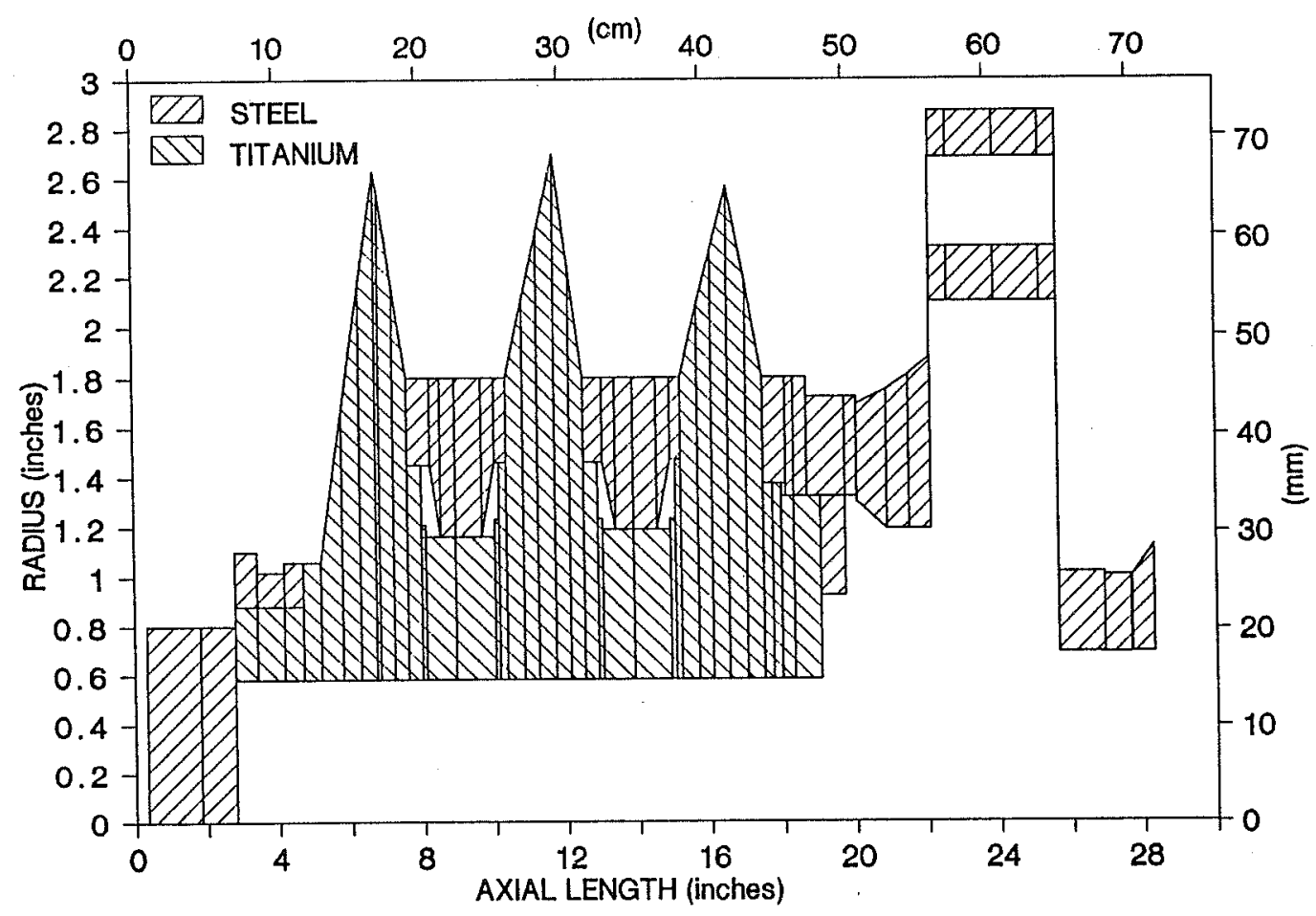

FIGURE 2. SSME HPFTP ROTORDYNAMIC SHAFT ELASTIC MODEL. 


\section{TURBINE SIDELOAD VARIATION}

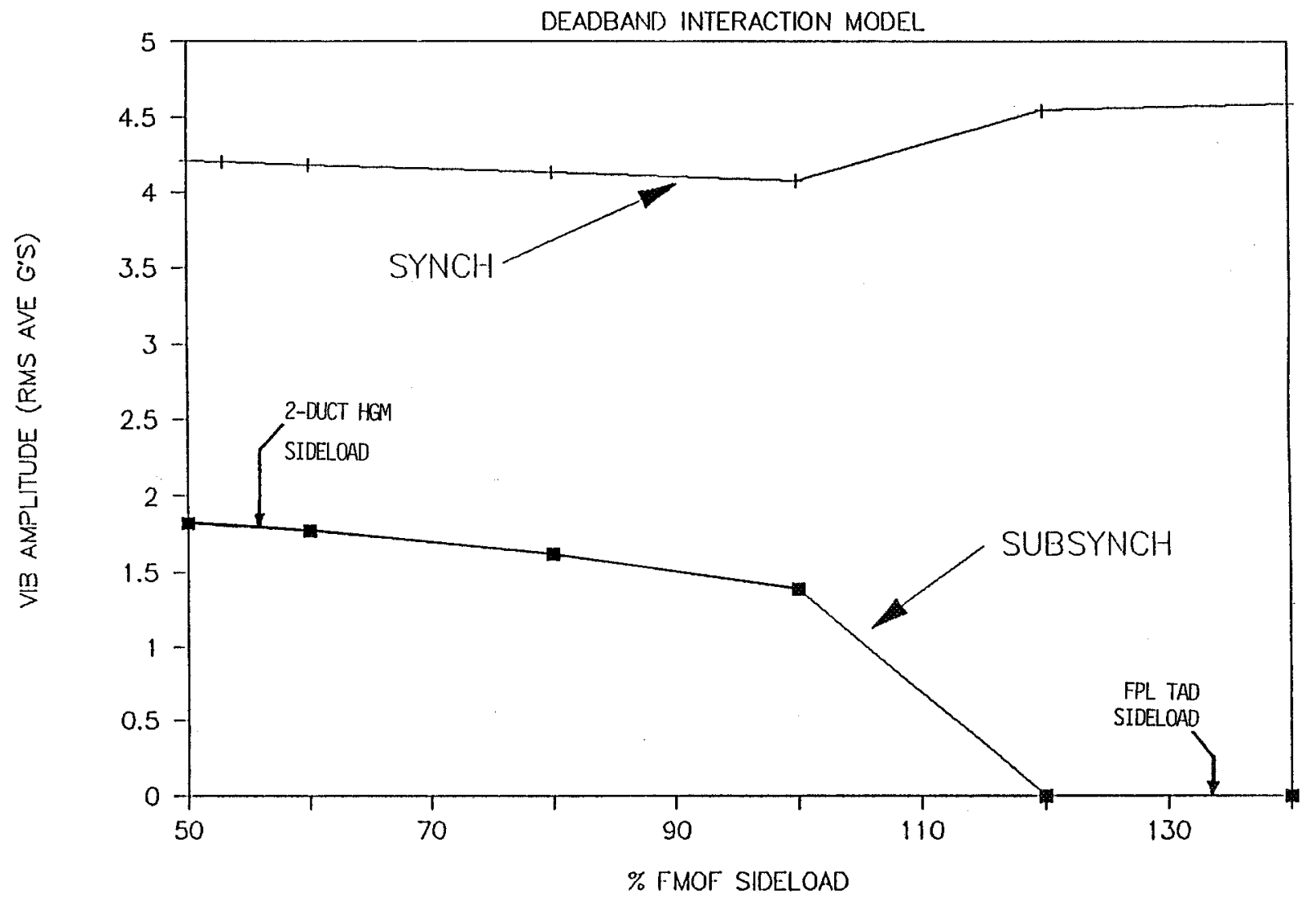

FIGURE 3. TURBINE SIDELOAD INFLUENCE ON VIBRATION AMPLITUDE 

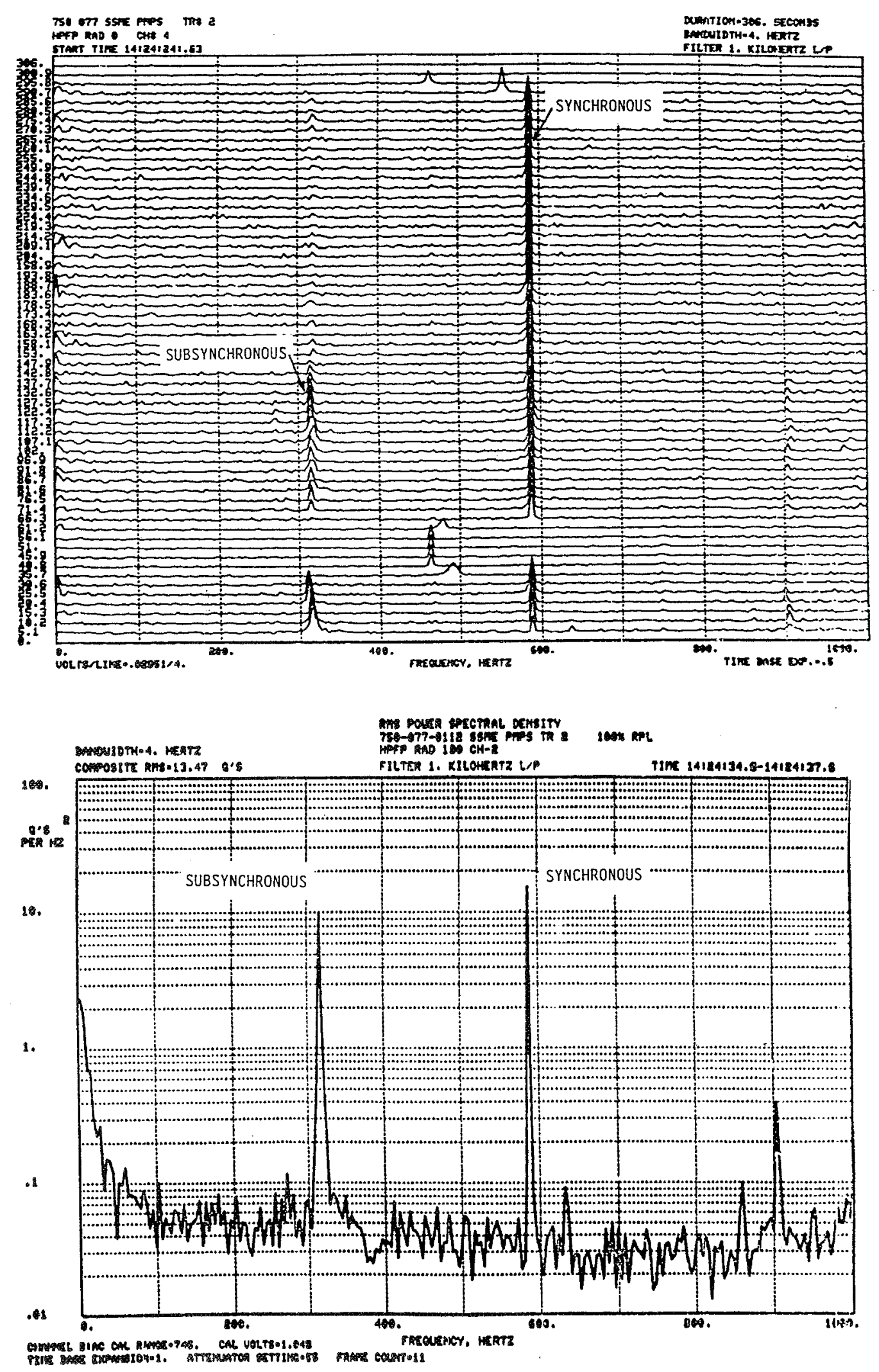

FIGURE 4. TURBOPUMP VIBRATION SPECTRA WITH

3-STEPPED I/S SEALS, FMOF TAD 

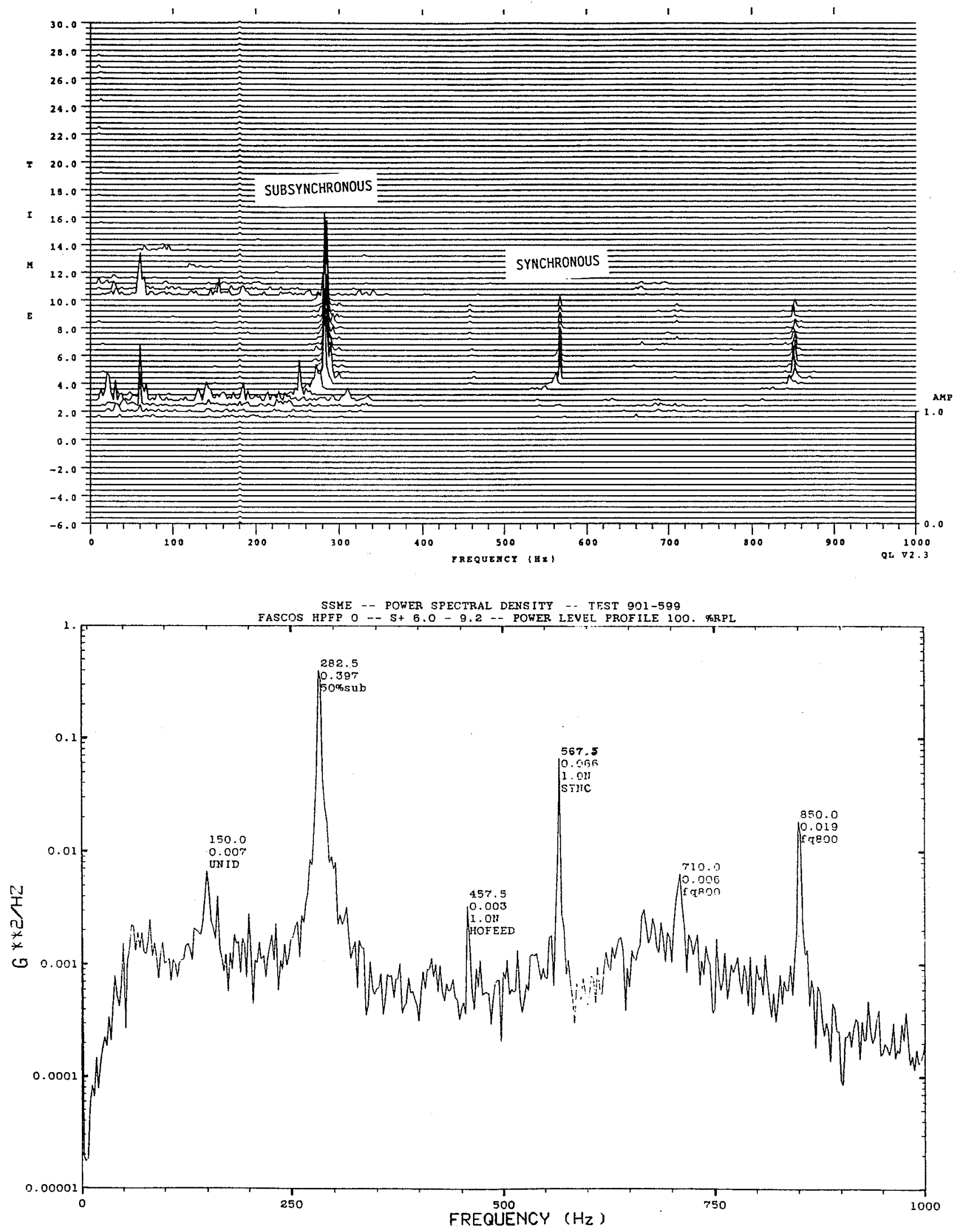

FIGURE 5. TURBOPUMP VIBRATION SPECTRA WITH STR-SMOOTH I/S SEALS, 2-DUCT HGM 

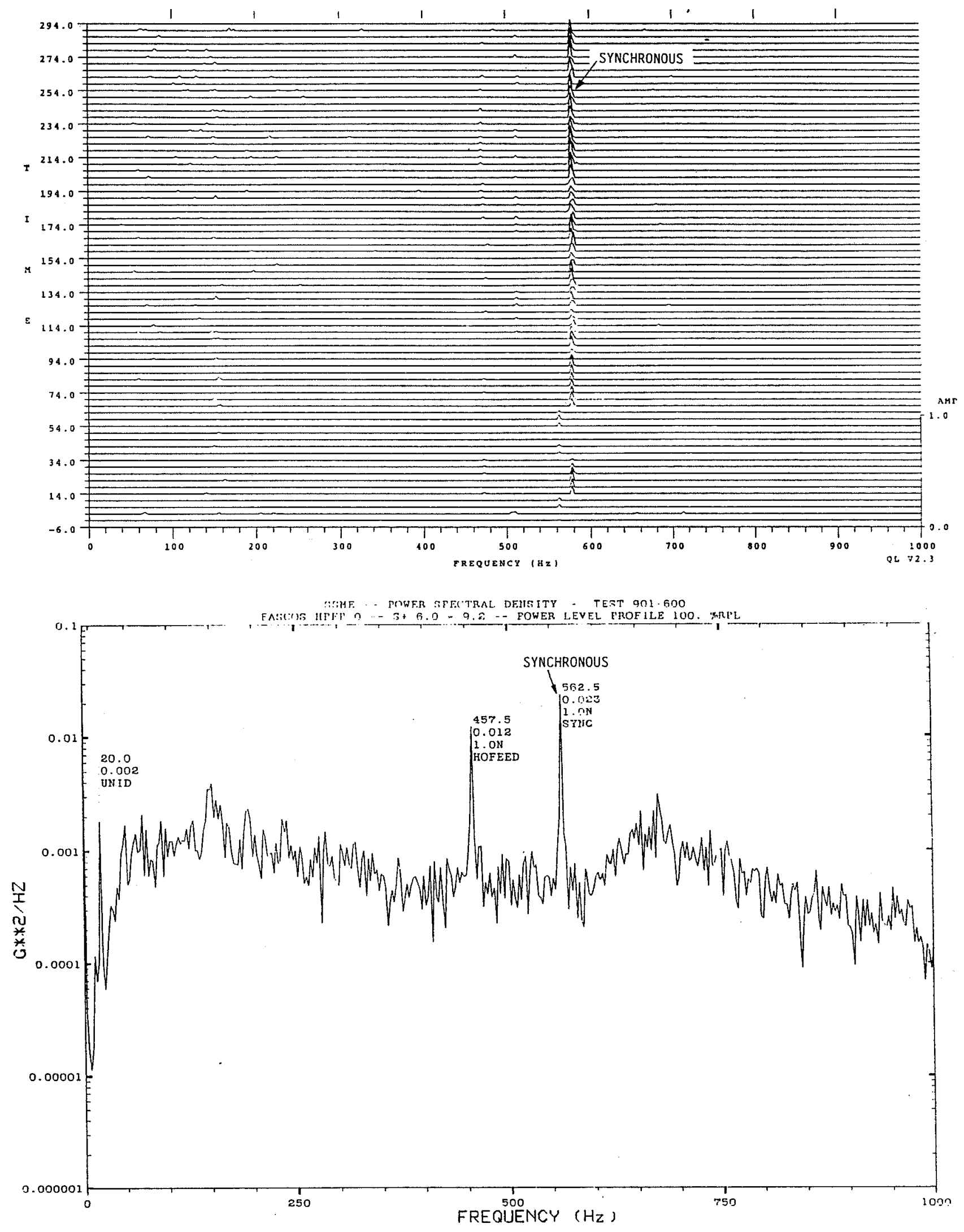

FIGURE 6. TURBOPUMP VIBRATION SPECTRA WITH STR-ROUGH I/S SEALS, 2-DUCT HGM 